\title{
O DESENVOLVIMENTO INFANTIL
}

\author{
Cleunice Carvalho da Rosa Tancredi ${ }^{1}$ \\ Jóici Pinheiro da Silva ${ }^{2}$ \\ Kely Cristina da Silva ${ }^{3}$ \\ Marilene Maria Schnorr ${ }^{4}$ \\ Mirela Nogueira dos Santos ${ }^{5}$ \\ Raquel de Almeida Santos ${ }^{6}$ \\ Rosangela Kovalski da Cruz Lima ${ }^{7}$
}

RESUMO: Este artigo discute o desenvolvimento da linguagem na infância, bem como os aspectos cognitivos, físicos, motores e emocionais, todos de importância primordial para o surgimento da linguagem. Os objetivos do mesmo são compreender o desenvolvimento infantil como um longo processo no qual existem vários símbolos e identificar e compreender como a aquisição da linguagem é estimulada, em cada fase do desenvolvimento infantil, com a participação de diferentes componentes. como a família, a escola, o ambiente externo e interno e o contato da criança com a sociedade como um todo. Aos 5 anos, as crianças já dominam os sistemas sonoros e gramaticais da linguagem e adquiriram um vocabulário de milhares de palavras. Este artigo descreve as principais etapas do desenvolvimento da linguagem durante os primeiros anos de vida da criança.

Palavras-chave: Desenvolvimento. Infância. Linguagem.

ABSTRACT: This article discusses the development of language in childhood, as well as the cognitive, physical, motor and emotional aspects, all of primary importance for the emergence of language. Its objectives are to understand child development as a long process in which there are several symbols and to identify and understand how language acquisition is stimulated, at each stage of child development, with the participation of different components. such as the family, the school, the external and internal environment and the child's contact with society as a whole. By age 5 , children have mastered the sound and grammatical systems of language and have acquired a vocabulary of thousands of words. This article describes the main stages of language development during the first years of a child's life.

Keywords: Development. Childhood. Language.

\footnotetext{
${ }^{1}$ Graduada em Pedagogia pela Universidade Norte do Paraná - UNOPAR, Especialista em Atendimento Educacional Especializado - AEE pela Faculdade das Águas Emendadas - FAE, Especialista em Docência na Educação Infantil pela Universidade Federal de Mato Grosso - UFMT.

${ }^{2}$ Graduada em Pedagogia pelas Faculdades Integradas de Ariquemes - FIAR.

${ }^{3}$ Graduada em Artes Visuais pelo Centro Universitário Internacional - UNINTER, Especialista em Ensino de Artes pela Faculdade Única de Ipatinga.

${ }^{4}$ Graduada em Pedagogia pela Faculdade Luterana no Brasil - ULBRA, Especialista em Psicopedagogia pela Faculdades das águas Emendadas - FAE.

${ }^{5}$ Graduada em Educação Artística - Habilitação em Música pela Universidade Federal de Mato Grosso - UFMT, Especialista em Atendimento Educacional Especializado - AEE pela Faculdade de Águas Claras.

${ }^{6}$ Graduada em Pedagogia pela Universidade de Várzea Grande - UNIVAG, Especialista em Educação Infantil pela Faculdade Afirmativo.

${ }^{7}$ Formação acadêmica Magistério pela Escola de zo Grau Darwin Monteiro da Silva.
} 


\section{INTRODUÇÃO}

Segundo Marcondes (1980), desenvolvimento é o aumento da capacidade do indivíduo na realização das funções complexas. O desenvolvimento infantil é um processo que tem início na vida intrauterina envolvendo o crescimento físico, a maturação neurológica, habilidades relacionadas ao comportamento, visando tornar a criança competente para resolver às suas necessidades a às do seu meio.

O desenvolvimento humano é dinâmico, com mudanças biológicas e psicológicas que permitem que a criança adquira novos comportamentos e também modifique os antigos. Com isso o desenvolvimento neuropsicomotor corresponde à aquisição progressiva de capacidades motoras e psicocognitiva de modo ordenado e sequencial (PIAGET, 1980).

No Brasil, em I984 e em 2002, foram lançados manuais técnicos pelo Ministério da Saúde destinados ao monitoramento do desenvolvimento infantil. O objetivo desses manuais foi oferecer uma ficha de acompanhamento do desenvolvimento que sirva como roteiro de observação e identificação de criança com prováveis problemas de desenvolvimento. Composta pelo marco do desenvolvimento infantil e também indicador psíquico. O desenvolvimento da linguagem no Brasil ainda é um pouco abaixo do monitoramento dos países desenvolvidos. Muitos dos quais possuem padrões de monitoramento específicos (PAPAILA 200I).

A linguagem sofre influência contínua de fatores externos genéticos, ambientais que apresentam variações de um indivíduo para o outro e que tornam único o curso do desenvolvimento de cada criança. Alguns fatores são de boa relevância quanto os achados para o desenvolvimento da linguagem, especialmente nos períodos perinatal e neonatal, são prematuridade, gestação de alto risco, relação negativa entre mãe e feto ,idade materna, assistência pré-natal precária, baixo peso ao nascer, comprimento menor que $45 \mathrm{~cm}$,asfixia perinatal, hemorragia intracraniana infecções congênitas, período de aleitamento materno menor que seis meses e baixa escolaridade materna(SOUZA 2002).

Os primeiros anos de vida são muito importa ntes devido à intensa atividade cerebral, fruto da interação entre as características biológicas e as oportunidades de experiência dos indivíduos. A intensa neuroplasticidade nesse período é também responsável por melhores prognósticos, se a intervenção acontecer de modo precoce. 
No Brasil que estudos mostram as influências da condição social, do fator desnutrição e da relação familiar como fatores de risco para o atraso do desenvolvimento neuropsicomotor da criança (GUTTON 2005).

A supervisão do crescimento e do desenvolvimento da criança é uma importante tarefa que faz parte do rol de atividades do dia-a-dia do pediatra. $O$ maior objetivo da identificação e do diagnóstico precoce do atraso do desenvolvimento de uma criança, e da consequente intervenção precoce, geralmente multiprofissional, ela contribui para que cada criança adquira seu máximo potencial individual, com finalidade da Pediatria (MÉIER 2013).

O acompanhamento de crianças e do processo de desenvolvimento reúne diferentes modalidades de avaliação, que incluem os pais, os professores os pediatras e os demais profissionais.

Reunindo ambos profissionais de saúde. Este acompanhamento é utilizado a anamnese, observação da criança em seu ambiente, a prática de atividade ou, ainda, a aplicação de instrumentos de triagem (LEMOS 1986).

Não existe um instrumento padronizado, isto dificulta a avaliação do 1803 desenvolvimento, o que tem contribuído para que as alterações passem despercebidas, isto se torna evidente muito anos mais tarde. Possivelmente quando a criança está no ensino fundamental. A aquisição da linguagem é uma das realizações mais notáveis dos primeiros anos de vida. Aos cinco anos de idade, as crianças têm o domínio essencial do sistema de sons e da gramática de seu idioma e adquiriram um vocabulário de milhares de palavras. Este trabalho descreve os principais marcos do desenvolvimento da linguagem presentes nos cinco primeiros anos de vida, em crianças monolíngues com desenvolvimento típico, e os mecanismos que têm sido propostos para explicar essas aquisições (HAGE 2004).

As habilidades de linguagem de crianças pequenas são importantes para seu sucesso interpessoal acadêmico. É essencial, portanto, dispor de descrições do desenvolvimento normativo que permitam identificação de crianças com comprometimento de linguagem e compreender os mecanismos de aquisição da linguagem que podem fornecer a base para a otimização do desenvolvimento de todas as crianças 


\section{DESENVOLVIMENTO}

\section{I Etapas do desenvolvimento social}

O ser humano nasce e se desenvolve com auxílio de suas respostas inatas, como por exemplo, o ato de mamar para saciar a fome. Com o passar do tempo ele adquire habilidades que lhe permitirão o convívio em sociedade. Na sociedade contemporânea é muito comum a entrada da criança, ainda em sua fase bebê dentro do ambiente escolar, decorrente do fato dos pais trabalharem o dia todo para a sustentação de sua família.

A sociedade possui um modelo não mais conservador de estrutura familiar onde a mãe ficava em casa para cuidar de seus filhos e o pai era o núcleo do sustento família (VYGOTSKY, 1996).

A criança desde o início de sua vida está em constante e profunda transformação. Primeiramente as respostas das crianças são dominadas por processos naturais e é através dos adultos que os processos psicológicos mais complexos tomam formam.

Dessa forma, a aprendizagem da criança inicia-se muito antes de sua entrada na escola, uma vez que, ela já está exposta desde o primeiro dia de vida aos elementos do seu sistema cultural, e à presença do outro se torna indispensável para a mediação entre ela e a cultura (DANTAS, 1990).

A entrada da criança na escola, o contato com a diversidade por meio da interação com as outras crianças e da aprendizagem de novos conhecimentos para se relacionar com o mundo real. É nesse universo é necessário compreender a importância do desenvolvimento humano e perceber que a criança não é um adulto em miniatura e que essas tem características próprias de sua idade, ou seja, existem modos de perceber, compreender e se comportar diante do mundo Piaget diz que existe uma assimilação progressiva do meio ambiente, que implica acomodação das estruturas mentais a este novo dado do mundo exterior (BOOK, 1996).

O desenvolvimento do indivíduo não se faz apenas no ambiente escolar, existindo a interação de diversos fatores, como a hereditariedade, crescimento orgânico, maturação neurofisiológica e o meio social (VYGOTSKY, 1996).

O desenvolvimento humano deve ser entendido como uma globalidade e que tem sido abordado a partir dos aspectos: físico-motor, intelectual, afetivo-emocional e social. 
Para Bruneras teorias do desenvolvimento humano parte do pressuposto de os quatro aspectos são indissociáveis, mas elas podem enfatizar aspectos diferentes, isto é estudar o desenvolvimento global a partir da ênfase em um dos aspectos quanto ao desenvolvimento intelectual (BRUNER, 1989).

Piaget; divide os períodos do desenvolvimento conforme o surgimento de novas qualidades do pensamento, o que por sua vez, interfere no desenvolvimento global onde cada período é caracterizado por aquilo que melhor o indivíduo consegue realizar nessas faixas etárias (PIAGET, 1967).

Todos os indivíduos passam por essas fases ou períodos, nessa sequência, sendo que, o início e o término de cada uma delas, depende das características biológicas do indivíduo e dos fatores educacionais e sociais.

Portanto, a divisão nessa faixa etária é uma referência que pode variar de indivíduo para indivíduo.

\subsection{Etapas do desenvolvimento da linguagem}

O desenvolvimento da linguagem na infância é um tema de interesse desde a antiguidade, e o foco de uma quantidade substancial de pesquisa científica desde a década de 1980.

A criança quando nasce não entende o que lhe é dito. Aos poucos atribui sentido ao que escuta. Da mesma maneira ocorre com a produção da linguagem falada. $O$ entendimento e a produção da linguagem falada evoluem. Existem diferentes tipos de linguagem: a corporal, a falada, a escrita e a gráfica. Para se comunicar a criança usa a linguagem corporal (mímica, gestos, etc.) e a linguagem falada, embora que ainda não fale, produz linguagem.

Steven Pinker (1954) em seu livro chamado "o instinto da linguagem: como a mente cria a linguagem”, explicando como linguagem funciona, como as crianças aprendem, como ela muda, como o cérebro a computa, como ela evoluiu.

Pinker (1954) diz que: "Linguagem é um instinto humano instalado em nosso cérebro, ou seja, existe um dispositivo que é ativado na mente quando a criança alcança certa idade, por isso lembramos apenas de certo momento de nossa infância”. 
Para Farias (2003) a manifestação da linguagem resulta em modificações importantes nos aspectos cognitivos, afetivos e sociais da criança, ela possibilita as interações humanas e fornece, especialmente, a capacidade de trabalhar com representações para atribuir significados à realidade. Tanto é assim, que a aceleração do alcance do pensamento neste estágio do desenvolvimento, é atribuída, em grande parte, às possibilidades de contatos interindividuais fornecidos pela linguagem, e é aqui o papel fundamental da escola com a inserção de atividades lúdicas no contexto escolar, ampliando o leque de possibilidades do desenvolvimento global do indivíduo.

Segundo Book (1996) o alcance do pensamento apresente transformações importantes, ele caracteriza-se, ainda, pelo egocentrismo, uma vez que a criança não concebe uma realidade da qual não faça parte, devido à ausência de esquemas conceituais e da lógica. O desenvolvimento da linguagem se divide em dois estádios: pré-linguístico, quando o bebê usa de modo comunicativo os sons, sem palavras ou gramática; e o linguístico, quando usa palavras. No estádio pré-linguístico a criança, de princípio, usa o choro para se comunicar, podendo ser rica em expressão emocional. Logo ao nascer este choro ainda é indiferenciado, porque nem a mãe sabe o que ele significa, mas aos poucos

ficar cheio de significados e é possível, pelo menos para a mãe, saber se o bebê está chorando de fome, de cólica, por estar se sentindo desconfortável, por querer colo etc.

Segundo Del Ré (2006) o balbucio ocorre de repente, por volta dos 6-ro meses, e caracteriza-se pela produção e repetição de sons de consoantes e vogais como "ma -ma ma -ma”, que muitas vezes é confundido com a primeira palavra do bebê. No desenvolvimento da linguagem, os bebês começam imitando casualmente os sons que ouvem, através da ecolalia. Por exemplo: os bebês repetem repetidas vezes os sons como o "da - da - da", ou "ma - ma - ma - ma". Por isso as crianças que tem problema de audição, não evoluem para além do balbucio, já que não são capazes de escutar.

Sampaio (2003) cita que por volta dos io meses, os bebês imitam deliberadamente os sons que ouvem, deixando clara a importância da estimulação externa para o desenvolvimento da linguagem. Ao final do primeiro ano, o bebê já tem certa noção de comunicação, uma ideia de referência e um conjunto de sinais para se comunicar com aqueles que cuidam dele. O estádio linguístico está pronto para se estabelecer. Dessa 
forma assim, contando com a maturação do aparelho fonador da criança e da sua aprendizagem anterior, ela inicia a dizer suas primeiras palavras.

Para Sciar-Cabral(199I) a fala linguística se inicia geralmente no final do segundo ano, quando a criança pronuncia a mesma combinação de sons para se referir a uma pessoa, um objeto, um animal ou um acontecimento. Por exemplo, se a criança disser apo quando vir a água na mamadeira, no copo, na torneira, no banheiro etc., pode afirmar que ela já está falando através de palavras.

Espera-se que aos 18 meses que a criança tenha um vocabulário aproximado de 50 palavras, no entanto ainda apresenta características da fala pré-linguística e não revela frustração se não for compreendida.

De acordo Piaget (197I) é na fase inicial da fala linguística a criança costuma dizer uma única palavra, atribuindo a ela, no entanto o valor de frase. Por exemplo, diz ua, apontando para porta de casa, expressando um pensamento completo; eu quero ir pra rua. Essas palavras com valor de frases são chamadas holófrases. A partir daqui acontece uma “explosão de nomes”, e o vocabulário cresce muito. Aos 2 anos espera-se que as crianças sejam capazes de utilizar um vocabulário de mais de cem palavras. Entre os 2 e 3 anos as crianças começam a adquirir os primeiros fundamentos de sintaxe, começando assim a se preocupar com as regras gramaticais.

Usam, para tanto, o que chamamos de super-regularização, que é uma aplicação das regras gramaticais a todos os casos, sem considerar as exceções. É por isso que a criança quer comprar “pães”, trazê-los nas "mães”. Aos 6 anos a criança fala utilizando frases longas, tentando utilizar corretamente as normas gramaticais.

Chomsky (1998) defende a ideia de que a estrutura da linguagem é, em grande parte, especificada biologicamente (nativista). Skinner (1954) diz que a linguagem é aprendida inteiramente por meio de experiência (empirista). Piaget (I97I) consegue chegar mais perto de uma compreensão do desenvolvimento da linguagem que atenda melhor a realidade observada. Para este mesmo autor tanto o biológico quanto as interações com o mundo social são importantes para o desenvolvimento da linguagem (interacionista).

Em geral, o curso do desenvolvimento da linguagem e seus mecanismos subjacentes são descritos separadamente para os subdomínios do desenvolvimento fonológico (o sistema de sons), do desenvolvimento léxico (as palavras), e do desenvolvimento 
morfossintático (a gramática), embora essas áreas estejam inter-relacionadas no desenvolvimento, assim como no uso da linguagem.

\subsection{Desenvolvimento fonológico}

Os recém-nascidos têm a capacidade de ouvir e discriminar os sons da fala. Durante o primeiro ano de vida, tornam-se mais competentes para escutar os contrastes usados em seu idioma e insensíveis às diferenças acústicas que não são relevantes para esse idioma. Esta sintonização da percepção da fala ao ambiente linguístico resulta de um processo de aprendizagem no qual os bebês formam categorias mentais de sons da fala em torno de grupos de sinais acústicos que ocorrem com mais frequência em seu idioma. Essas categorias, orientam a percepção, de modo que as variações dentro de uma categoria são ignoradas, e as variações entre as categorias são percebidas.

Os primeiros sons que os bebês produzem são gritinhos e ruídos que não se assemelham à fala. Os principais marcos do desenvolvimento vocal anterior à fala são a produção de sílabas canônicas (combinações adequadas de consoantes e vogais), que aparecem entre os seis e os io meses de idade, rapidamente sucedidas por balbucios duplicados (repetições de sílabas).

Quando aparecem as primeiras palavras, são utilizados os mesmos sons, e as palavras contêm o mesmo número de sons e de sílabas, que as sequências precedentes do balbucio.

Um dos processos que contribuem para o desenvolvimento fonológico inicial parece ser o esforço ativo dos bebês de reproduzir os sons que escutam. No balbucio, os bebês podem descobrir a correspondência entre o que fazem com seu aparelho vocal e os sons resultantes. O importante papel do feedback é sugerido por observações de que crianças que têm perdas auditivas apresentam atraso na produção do balbucio canônico.

Aos 18 meses de idade, as crianças constroem um sistema mental para representar os sons de seu idioma e para produzi-los dentro das limitações de suas capacidades de articulação. A produção de sons da fala pelas crianças torna-se consistente nas diferentes palavras em contraste com o período anterior, em que a forma de som para cada palavra era uma entidade mental separada. Os processos subjacentes a este desenvolvimento ainda não são suficiente compreendidos. 


\subsection{Desenvolvimento léxico}

Os bebês entendem as primeiras palavras por volta dos cinco meses de idade, produzindo as primeiras palavras entre io e 15 meses, atingindo o marco de 50 palavras de vocabulário produtivo por voltados 18 meses, e o de 100 palavras entre 20 e 2I meses. Depois disso, o desenvolvimento do vocabulário é tão rápido que se torna praticamente inviável rastrear quantas palavras as crianças conhecem. $\mathrm{O}$ vocabulário de uma criança de aproximadamente seis anos de idade foi estimado em 14 mil palavras.

A tarefa de aprendizagem de palavras tem múltiplos componentes e recorre a múltiplos mecanismos. Os bebês utilizam procedimentos estatísticos de aprendizagem, monitorando a probabilidade de que os sons apareçam juntos e, dessa forma, segmentam o fluxo contínuo da fala em palavras separadas. A capacidade de armazenar essas sequências de sons da fala, conhecida como memória fonológica, entra em ação à medida que são criadas entradas no léxico mental.

Na tarefa de mapear uma palavra nova em relação a seu referente, as crianças são conduzidas por sua capacidade de usar mecanismos de inferência socialmente baseada (isto

é, as crianças falantes falam sobre coisas para as quais estão olhando), pelo seu conhecimento de mundo (parte da aprendizagem de palavras envolveu o mapeamento de novas palavras em conceitos pré existentes) e por seu conhecimento linguístico anterior (isto é, a estrutura da frase na qual uma nova palavra permite pistas acerca do significado dessa palavra). O domínio completo do significado das palavras exige também novos desenvolvimentos conceituais.

\subsection{Desenvolvimento morfossintático}

Aos 24 meses de idade, a criança começa a reunir duas, três ou mais palavras em frases curtas. As primeiras frases são combinações de palavras de conteúdo, e frequentemente não estão incluídas palavras com função gramatical, por exemplo, artigos e preposições nem terminações de palavras, por exemplo, marcadores de plural e de tempo. $\mathrm{Na}$ medida que domina a gramática de seu idioma, a criança tem a capacidade de produzir enunciados cada vez mais extensos e gramaticais. De modo geral, o desenvolvimento de períodos complexos, isto é, com várias orações inicia um pouco antes do segundo 
aniversário, se tornado completo aos quatro anos de idade, ou seja, geralmente, a compreensão precede a produção.

O mecanismo responsável pelo desenvolvimento da gramática é um dos temas mais debatidos no estudo relacionados ao desenvolvimento da linguagem. As crianças enfrentam a tarefa de aprendizagem da linguagem com o conhecimento inato da estrutura da linguagem, e que a linguagem não poderia ser adquirida de outro modo.

No entanto, também é evidente que, mesmo na infância, as crianças são capazes de detectar padrões abstratos na fala que ouvem, e existem evidências muito sólidas de que as crianças mais expostas à fala e que ouvem enunciados estruturalmente mais complexos adquirem a gramática mais rapidamente do que crianças com menos experiências, o que sugere que a experiência linguística desempenha um papel substancial no desenvolvimento da linguagem.

Nesta área, existe uma carência, ou desconexão, entre a busca teórica para explicar o fato universal da aquisição da linguagem e a necessidade prática de compreender as causas das diferenças individuais no desenvolvimento da linguagem.

Existe poucas pesquisas acerca das populações minoritárias e do desenvolvimento bilíngue que acerca da aquisição de um único idioma em amostras de classe média. Esta é uma lacuna, uma vez que a maioria dos instrumentos de avaliação padronizados não é adequada para identificar atrasos ocasionados por motivos orgânicas em crianças que pertencem a minorias, em crianças de estratos socioeconômicos mais baixos ou naquelas que adquirem mais de um idioma.

O curso do desenvolvimento da linguagem é semelhante entre crianças, e mesmo entre os idiomas, o que indica a existência de uma base biológica universal desta capacidade humana. A taxa de desenvolvimento é muito diversificada, e depende da quantidade e natureza das vivências linguísticas infantil quanto de suas capacidades de usar essas experiências.

As crianças com capacidades normais necessitam vivenciar interações conversacionais para adquirir a linguagem. No entanto, diversas crianças não tenhem experiências necessárias relacionada a essa interação para maximizar seu desenvolvimento de linguagem. Os pais precisam ser encorajados a tratar seus filhos pequenos como parceiros de conversa desde os primeiros meses de vida. 
Educadores e formuladores de políticas devem reconhecer que as habilidades linguísticas das crianças não refletem simplesmente suas capacidades cognitivas, mas também as oportunidades de ouvir e usar a linguagem que seus ambientes lhes proporcionaram.

\subsection{Desenvolvimento semântico}

Ao analisar o aspecto semântico da linguagem, analisa-se como a criança domina o significado das palavras e as combinações de palavras. Para Acosta et al (2003) o desenvolvimento semântico precisa ser analisado dois processos básicos da linguagem: a compreensão e a produção, diferenciados como vocabulário expressivo e compreensivo. Em relação à compreensão, ao reconhecimento de palavras, locuções e frases que a criança tem.

A avaliação da compreensão, nos primeiros anos de vida, é realizada através de atividades motoras da criança. Quanto à produção "o conteúdo da linguagem é expresso mediante elementos formais: seleção de palavras adequadas para referir-se a pessoas, animais, objetos e ações, entonação pertinente e organização adequada dos elementos na

frase para expressar ideias, conceitos, sentimentos, sensações, etc”. É preciso avaliar as produções de linguagem da criança, que possibilita verificar a complexidade semântica apresentada pela criança e se é compatível com o desenvolvimento normal (BARBEIRO 2000).

\section{CONCLUSÃO}

Considera-se o crescimento da criança como um fator relacionado em todos os aspectos, porque é necessário ter o desenvolvimento na integração, significado para falar sociedade, psicologia, então o que precisa existem condições que podem ser fornecidas à criança com segurança social desenvolvimento e também desenvolver sua capacidade de aprendizagem para respeitar os limites de cada idade.

A criança prevê que é desenvolvida de forma relevante e dinâmica, o desenvolvimento físico corresponde ao desenvolvimento de elementos genéticos e biológicos que impedem esse processo. O desenvolvimento social e emocional é outro fator relacionado que deve ser considerado um parceiro específico no processo de aprendizagem. 
A personalidade da pessoa é única e sua construção ocorre nos primeiros anos de vida. A base deste desenvolvimento trará a estrutura de infância, adolescentes, jovens e maduros. Por isso, cuidar de crianças é importante para o seu desenvolvimento emocional saudável.

Conhecer o mundo e se sentir seguro é essencial para quem acabou de vivenciar um trauma de parto e entrou no mundo real. Nesta fase, o mais importante é estabelecer um vínculo mãe-filho para que seu bebê se sinta seguro e continue sua aventura de descobrir o mundo.

Crianças com habilidades normais precisam apenas de experiências interativas e de conversação para adquirir a linguagem. No entanto, muitas crianças podem não ter experiência suficiente com esse tipo de interação para o desenvolvimento máximo da linguagem. Os pais devem ser incentivados a tratar seus filhos como interlocutores desde os primeiros meses de vida.

Educadores e formuladores de políticas devem reconhecer que as habilidades linguísticas das crianças refletem não apenas suas habilidades cognitivas, mas também suas oportunidades de ouvir e usar a linguagem que seu ambiente oferece.

\section{REFERÊNCIAS}

ARIES, P. História Social da Criança e da Família. 2. ed. Rio de Janeiro: LTC, I98I.

BARBEIRO, L. (2000). Com a linguagem: do lado dos sons. Leiria: Legenda. (pp. ir6 a I24).

BRUNER, J. Acción. Pensamiento e lenguaje. Madrid. Alianza, 1989.

CHOMSKY, Noam. Linguagem e mente. Brasília: Universidade de Brasília 1998.

LEMOS, C.T.G. Interacionismo e aquisição de linguagem. D.E.L.T.A., 2 (2): 231-48, São Paulo; 1986.

GOUlART, B. N. G., \& CHIARI, B. M. (2007). Prevalência de desordens de fala em escolares e fatores associados. Revista de Saúde Pública, 4I(5), 726-73I.

HAGE S. Avaliando a linguagem na ausência de oralidade. Editora da Universidade do Sagrado Coração, 2004 .

PIAGET, J. A Construção do Real. Rio de Janeiro: Zahar, 1967. 
PIAGET, J. A formação do símbolo na criança, imitação, jogo, sonho, imagem e representação de jogo. São Paulo: Zahar, 1971.

CABRAL Leonor. Introdução à psicolinguística. ED. Ática, I99I.

VYGOTSKY, L. S. A Formação Social da Mente. Rio de Janeiro: Martins Fontes, 1996.

WALlON, H. As Etapas da Socialização da Criança. Lisboa, 1953. 